\title{
The Construction and Standardization of a Domestic Violence Questionnaire
}

\author{
Khadijeh Abolmaali*, Hayedeh Saberi, Sousan Saber \\ Department of Psychology, Roudehen Branch, Islamic Azad University, Roudehen, Iran \\ Email: ${ }^{\text {sama.abolmaali@gmail.com }}$
}

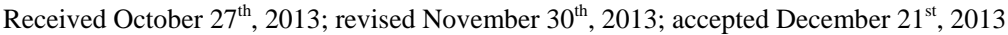

\begin{abstract}
Copyright (c) 2014 Khadijeh Abolmaali et al. This is an open access article distributed under the Creative Commons Attribution License, which permits unrestricted use, distribution, and reproduction in any medium, provided the original work is properly cited. In accordance of the Creative Commons Attribution License all Copyrights (C) 2014 are reserved for SCIRP and the owner of the intellectual property Khadijeh Abolmaali et al. All Copyright $(\subset) 2014$ are guarded by law and by SCIRP as a guardian.
\end{abstract}

\begin{abstract}
The purpose of this research was to standardize the self-reported domestic violence scale. 530 participants were randomly selected via clustered sampling methods from married students of The Islamic Azad University of district 8 in Iran. According to this scale, a total score was measured for domestic violence and also, based on exploratory factor analysis, 2 scores were measured for two dimensions of domestic violence, and these dimensions are: 1) Psycho-physical violence, 2) Control violence (sexual, economic, coercive violence). The reliability of this test was measured with internal consistency $(\alpha=0.915)$ and the test retest method $(r=0.987)$. The criterion validity of this scale was significant and this scale had a significant relationship with the quality of marital life test. This scale can be used by psychologists and researchers for diagnostic assessment, intervening programs and identification of domestic violence dimensions.
\end{abstract}

Keywords: Domestic Violence Scale; Psycho-Physical Violence; Control Violence; Standardization; Reliability; Validity

\section{Introduction}

The term "domestic violence" which is sometimes called family violence is an interpersonal violence including the aggressive behaviour and actions between family members and it may happen among couples, children, parents, old people, sisters and/or brothers (Hollin \& Bloxsom, 2007). Violence towards an intimate partner (IPV) is a global phenomenon that happens in many areas of the world (Campbell, 2003). IPV is a pattern of behaviours with compulsion that may include physical harm, psychological abuse, sexual annoyance, prevention of social relationships with family and friends, isolating and confining the partner from any social relationships, prosecution, privation, humiliation or threat (Family Violence Prevention, 1999). Violence towards the spouse has destructive consequences on the family climate and children, and it often takes place in four forms:

A. Physical violence towards the spouse includes actions such as an attack with a weapon, pushing, punching, slapping, kicking and throwing objects at the spouse; this can happen bilaterally between the couples.

B. Psychological abuse in domestically relationships, also referred to as emotional abuse, is characterized by several dimensions. These dimensions include threatening behavior: implicit or explicit, denigrating damage or under-mining a victim's self image or self esteem, passive aggressive withholding of emotional support and nurturance, restricting personal territory and freedom (Mariuro, 2001). The psychological abuse often does not occur clearly and it may have longitudinal and disruptive ef-

${ }^{*}$ Corresponding authors. fects on victims.

C. Sexual violence includes the unexpected sexual relationship such as hard or unusual and harsh sexual behaviours, forced sexual activities and the pressure to have sex.

D. Financial or economic violence includes behaviour such as maintaining control over finance, creating a barrier to spending money, withholding access to money, making the victim financially dependent, not allowing the victim to work, income control and taking credit card or spouse's money, interpellation for spending money and financial abuse by the offender (Abolmaali \& Mousazadeh, 2012).

Zosky (1999) has divided the determinant factors of domestic violence into three groups: Micro, Middle and Macro. In the micro level, intra-psychic processes influencing the adults' behaviour have been noticed. Some of these factors have been explained by experts and researchers, such as: schizophrenia and other psychotic disorders, mood disorders, drug abuse, impulsive control disorders, sexual and gender identity disorders, personality disorders and cognitive disorders such as delirium, dementia, and amnesia, anxiety disorders, adjustment disorders, premenstrual dysphoric disorder (Webester \& Hucker, 2007), deficits in social recognition (Abolmaali \& Mousazadeh, 2012), unsafe attachment styles, facing violence at childhood, (Rodriguez, 2006; Goudbout, Dutton, \& Lussier, 2009), childhood disorders, interpersonal sensitivity (Mohammadkhani \& Azadmehr, 2008), low self-esteem, background of PTSD and addiction to alcohol (Whiting, Simmons, Havens, Smith, \& Oka, 2009). Other researchers have considered the weakness of anger management and communicative skills in the appearance of the vi- 
olence towards the partner (Mohammadkhani, 2005). Winters, Clift and Dutton (2004) in a study showed that the scores of the offenders are lower in the components of emotional intelligence than others.

The family systems theory gives a description in the middle level of the processes and dynamics of interpersonal issues among domestic violence and its role with regard to this (Rodriguez, 2006). For instance, coercive control (CC) explains the patterns of sexual and economic compulsion where a partner controls the other one dominantly. Of course, it is stated that men usually do this action and pattern more. Intimidation, and isolating the partner and as well forbidding the comings and goings have been seen in the CC pattern (Jackson, 2009). Different patterns of the couples' relationships can be a reflection of culture in societies. It seems that in male-dominated cultures such as our society, the pattern of CC represents a suitable explanation for the middle domestic violence. Factors such as penalty background (Taheri, 2000), socio-economic status of family (Fattahi, 2000; Aghabigloie, Aghajani, \& Chehreii, 2002; Bagrezaiee, 2003), and family intervention (Arshi, 2004) can also have an influence in domestic violence.

In the Macro level, it often considers feminist perspectives. Feminists consider the whole objections and protests from the gender categorizations and male-dominated attitudes that lead to domestic violence (Zoski, 1999). In some cultures, women usually are considered as low-status people and any violence happens against them (Sterne \& Pool, 2010).

Violence towards the spouse happens in both genders; of course the studies have shown that most victims are women (Andarabi, 2009). Studies indicate that the violence towards women is being intensified due to their lifestyle and the lack of economic self-support and social supports in various situations (MirMajidi, 2009). Women also apply violence against their husbands; most men who have encountered violence feel reluctant to seek support (Stern \& Pool, 2010; Keeling \& Mason, 2009). The scenario of domestic violence against men is a subject that some researchers believe requires justice in this case. Moore (2008) believes that the number of men facing domestic violence is increasing. Due to the private territory of the families, the accurate statistics of the occurrence of domestic violence is not available in Iran and other societies. However, the highest degree of violence is related to the psychological violence towards women. For example, Occurrence of psychological violence was reported by Marabi (2007) 100\%, but Belali, Meibodi and Hassani (2009) reported an occurrence of $76.6 \%$ in their studies. In a national plan in Iran, conducted by the Ministry of Social Affairs and presidential women participation affairs in two provinces, verbal and psychological violence (52\%), physical violence (37.8\%), violence of prevention in social-educational relations and sexual violence (10\%) were estimated, respectively (Saeidzadeh, 2009). Marabi (2007) has reported the economic violence towards women is $81.6 \%$ in society. Of course, due to the nature of private and hidden issues of domestic violence, the violence may be occurring beyond the degree of the reported statistics.

One of the biggest challenges in the area of domestic violence is diagnosis and assessment of it. Therefore, construction of a suitable and precise questionnaire is a necessity for providing an opportunity to measure the occurrence of family violence, the prevention of family and children problems and intervention for the reduction or ceasing of it. Thus, the main question of this research is whether the domestic violence ques- tionnaire which was made by researchers has enough reliability and validity among married students from the university.

The main purpose of this study is to construct a valid and reliable tool for measuring domestic violence among married students and the special purposes are as follows:

1) Determining the validity (construct, criterion and differential validity) of the domestic violence questionnaire.

2) Determining reliability (internal consistency and test-retest reliability) of the domestic violence questionnaire.

3) Access to quantitative norms ( $\mathrm{T}$ standard scores and quartile scores) to determine the relative situation of people in the domestic violence questionnaire.

\section{Materials and Methods}

\section{Procedure}

The statistical population of the present study includes the married students in the $8^{\text {th }}$ district of The Islamic Azad University in 2012 Iran. In order to select a sample group, first all universities of the $8^{\text {th }}$ district 3 branches were chosen and then each branch was randomly selected from several educational fields, and then from each field, several classes were selected and all married students of these classes were tested.

\section{Instruments}

\section{Domestic Violence Questionnaire}

This is a self-report tool put together by the researchers. Domestic violence is a multi-dimensional structure and the considered dimensions of this questionnaire are including as follows:

1) Physical violence, 2) Psychological violence, 3) Sexual violence and 4) Economic violence.

In this research for each dimension several items were designed. In this questionnaire the response of each option is scored on a Likert scale: Not at all true of my spouse (0); slightly true of my spouse (1); moderately true of my spouse (2); very true of my spouse (3), and extremely true of my spouse (4). The highest score of this questionnaire shows the highest level of violence in this study.

\section{Hudson's Life Quality Questionnaire}

This test was standardized in a cross-sectional study on 520 couples dwelling in Tehran by Saberi and Abolmaali (2012). Based on factor analysis methods, only one cohesive factor significantly has been extracted. The concurrent validity of this scale was significant and this scale had a significant relationship with the test of life satisfaction. In addition, the differential validity of the test also showed it can recognize people suffering from the weak life quality. The reliability of the test was estimated by Cronbach's Alpha method 0.92 and by the test-retest reliability was 0.93 .

\section{Construction Steps and the Administering of the Domestic Violence Questionnaire}

For each field of domestic violence (psychological, economic, physical and sexual), some questions were designed based on their features. To determine the proportion and number of questions, it firstly referred to the occurrence statistics of domestic violence in Iran. But due to the lack of accurate statistics in this case, the researcher decided to evaluate the proportion of do- 
mestic violence occurrence via an introductory study. Based on this, 30 married students were selected from the statistical population as accessible and were interviewed; then, the proportion of each domestic violence field was determined due to the report of the degree of violence from them. Therefore, the related statistics were obtained: Psychological violence: 0.66, economic violence: 0.14 , sexual and physical violence: 0.10 . It should be mentioned that the determined proportions were only based on those peoples' experiences who participated in this experimental study. These proportions only represent experienced violence, not their importance with regard to this. After determining the proportion of questions, 120 questions were designed for the preliminary form. The validity of the preliminary form was studied based on the experts' views in this case. This questionnaire was administered in three steps: preliminary, experimental and final steps. In the preliminary step, the questionnaire with 120 items was administered on 30 people who were selected as available in this study. In this step the ambiguous questions were amended or removed and the number of questions was minimized to 110 with regard to this. In the experimental step, 110 items were administered on 150 people who were selected randomly from the statistical population. In this step, questions that have no significant correlation with the total score of the domestic violence test were eliminated. (That is, when Cronbach's alpha was negative or near to zero). Then, the number of the questions was minimized to 72. In the final step, the questionnaire was administered on 530 people that were randomly selected from the statistical population and entire psychometric analyses were fulfilled on the obtained data from the final version. The statistical indices of question analysis like reliability and validity of the test (via Cronbach's alpha and test-retest method) were measured. Construct validity of domestic violence was also estimated by the exploratory factor analysis and criterion validity. In this step, the number of the questions was minimized to 42 with regard to this.

\section{Results}

\section{Descriptions of the Domestic Violence Test and Its Factors among Men and Women}

After the factor analysis, the scores of the participants in the questionnaire were descripting, as shown in Table 1 for men and women separately.

It should be mentioned that of the 530 people that completed the test 371 of them were female and 159 were male. Based on the above mentioned table, the description of the scores in males and females (based on skewness and kurtosis) show that the distribution of scores tends towards the normal distribution. The mean total score of domestic violence in women is 15.45 and 10.86 in men, respectively. The mean score of psychophysical violence is 7.73 in the sample group and is 6.9 in females and 8 in males. The mean score of control violence is 4.96 and the total score is 3.9 and 7.43 related to males and females, respectively.

\section{The Evaluation of Test Validity}

\section{Content Validity}

In relation to this, after designing the preliminary question form, the experts confirmed the content of the test, according to 4 criteria: simplicity and clarity, scientific acceptance, necessity of the given questions and to pertain to the designed questions the purpose of the test. Then consistency of their comments was obtained as 0.961 .

\section{Construct Validity}

In order to evaluate the construct validity of the questionnaire and to access the constructs and possible factors, exploratory factor analysis with principal axis factoring based on Varimax rotation was used. According to the Kaiser-Meyer-Olkin Measure of Sampling and a degree of $\mathrm{KMO}=0.856$ and the approximate Chi-square degree in Bartlett's Test of Sphericity (10896.745) and $\mathrm{df}=2415$ and sig. $=0.000$, it is shown that the data has factorial ability with regard to this. The communality amount represents the degree of variable variance that is accounted for by the extracted factor and it shows the proportion of the extracted variance. The communality is the squared multiple correlation $\left(\mathrm{R}^{2}\right)$ between the test and the factor emerging from the factor analysis (Kinnear \& Gray, 2004). In this research the items with communalities lower than 0.2 were eliminated. Based on the scree plot and due to the Eigen values, more than two factors were shown, but in general when these questions were loaded under more than two factors, it does not introduce

Table 1.

Descriptions of the domestic violence test and its factors among men and women.

\begin{tabular}{|c|c|c|c|c|c|c|c|c|c|}
\hline \multirow{2}{*}{ Statistical indices } & \multicolumn{3}{|c|}{ Domestic violence questionnaire } & \multicolumn{3}{|c|}{ Psycho-physical violence } & \multicolumn{3}{|c|}{ Control violence } \\
\hline & $\mathrm{M}^{\mathrm{a}}$ & $\mathrm{W}^{\mathrm{b}}$ & $\mathrm{T}^{\mathrm{c}}$ & M & $\mathrm{W}$ & $\mathrm{T}$ & M & $\mathrm{W}$ & $\mathrm{T}$ \\
\hline Mean & 10.9 & 16 & 12. & 6.9 & 8 & 7.7 & 3.9 & 7.4 & 5 \\
\hline Median & 6 & 12 & 9 & 4 & 5 & 4 & 3 & 6 & 5 \\
\hline Variance & 154 & 17 & 16 & 82 & 75 & 87 & 19 & 31 & 25 \\
\hline $\mathrm{Sd}^{\mathrm{e}}$ & 12.4 & 13 & 13 & 9.1 & 8.7 & 9.3 & 4.3 & 7.5 & 4.9 \\
\hline Minimum & 0 & 0 & 0 & 0 & 0 & 0 & 0 & 0 & 0 \\
\hline Maximum & 54 & 52 & 54 & 38 & 34 & 39 & 21 & 23 & 23 \\
\hline Skewness & 1.7 & 1.2 & 1.4 & 1.1 & 1.4 & 1.6 & 1.1 & 0.8 & 1.2 \\
\hline Std error of skewness & 0.2 & 0.3 & 0.2 & 1.2 & 0.3 & 0.2 & 0.2 & 0.3 & 0.1 \\
\hline Kurtosis & 1.4 & 0.6 & 1.5 & 1.5 & 1.2 & 1.2 & 1.1 & 0.1 & 1.0 \\
\hline Std error of kurtosis & 0.4 & 0.5 & 0.3 & 0.4 & 0.6 & 0.3 & 0.4 & 0.5 & 0.3 \\
\hline
\end{tabular}

${ }^{\mathrm{a}}$ Men, ${ }^{\mathrm{b}}$ Women, ${ }^{\mathrm{c}}$ Total, ${ }^{\mathrm{e}}$ Standard deviation. 
an integrative and significant construct with regard to this. However, when the questions were loaded under two factors, two integrative and significant constructs are being introduced in this case. The first factor could explain a result of $15.54 \%$ and the second factor of $9.93 \%$ could explain the total score variance of the test. And these two factors explain $25.47 \%$ of the total variance of the test. Since the purpose of the factor analysis is to link variables together into factors, those variables must be related to one another and therefore have correlation coefficients larger than about 0.3 (Kinnear \& Gray, 2004: p. 411). In this research, the coefficient was considered as 0.4 (cut off point). In attention to the content of questions loaded under each factor, the first factor was labelled psycho-physical violence and the second factor was labelled control violence (sexual-economic-coercive). Finally, 42 questions remained in this test. The degree of communalities and factor load of questions are shown in Table 2 separately.

Based on the above mentioned table, the highest factorial load and communalities degree in the first and second factors are related to questions 38 and 20, respectively and the maximum and minimum factorial load and communalities in the second factor is subjected to questions 25 and 32 in this study as well.

\section{Criterion Validity}

In order to obtain the criterion validity, the couples' life quality test was used as external criteria with regard to this. In the below table, the correlation of total score with the score of domestic violence test and two factors were reported. The correlation of total score with the life quality test is -0.625 and the correlation of factors 1 and 2 are -0.69 and -0.56 , respectively and the level of significant is equal (sig. $=0.0000$ ) in this case.

\section{Deferential Validity}

In this research, 30 people had referred to Avin consultation centre for domestic violence in Tehran City and completed the domestic violence questionnaire. The mean total score of domestic violence was 42 , minimum 32 , maximum 72 and standard deviation was 10.86 in this study. According to the $t$ test in independent groups showed this test has the ability of separation in people with domestic violence with normal ones (sig. = 0.000).

\section{Reliability}

The reliability of the total test and each of the factors by Cronbach's alpha and test-retest was reported. By the use of Cronbach's alpha method, the entire reliability of the domestic violence test with 42 questions equals 0.915 . The reliability of the first factor (psycho-physical violence) with 28 questions equals 0.907 , and the second factor reliability (control violence) with 14 questions is 0.79 as a suitable degree. In order to anticipate the consistency and precision of the domestic violence scale, the test-retest method was applied during a two week period on 60 people and the correlation between these was computed twice and the reliability of the total test became 0.987 and in the first and second factors the degree got to 0.98 and 0.97 , respectively.

\section{Transformation of Test Scores}

$\mathrm{Z}$ and $\mathrm{T}$ score were accounted for obtaining a suitable norm.
These can be used for comparing scores of different individuals.

In the following Table 3, raw scores, $\mathrm{z}$ scores and $\mathrm{T}$ scores are shown.

In order to compare different individual's scores, quartiles of the total score of domestic violence and two factors have been reported. For the total score of domestic violence test and factor 1 and 2, Q1 is equal to 3, 2, 1; and Q2 is 9, 4 and 5; and for Q3 is 16,10 and 7, respectively. For comparison, domestic violence and 2 of their factors were applied to the test for independent samples.

\section{Discussion}

The main purpose of the study was to construct and account validity and reliability to the domestic violence questionnaire. Based on the obtained results, this scale is suitable for assessing domestic violence and its two components. According to Cronbach's alpha coefficient, this test has a satisfactory internal consistency. In addition, the accounting of reliability with test-retest method represents the degree of accuracy and stability of the test results over the time. According to the fact that domestic violence is a multi-dimensions structure (Ramirez, 2003), no violence figures were seen separately in this research. For example, in the first factor, psycho-physical violence, two dimensions were together as a multi-dimension structure. In the second factor, as it mentioned before, different dimensions of sexual-economic and coercive violence were loaded under factor 2. This result corresponds to Abolmaali's research (2012) that showed aggression is a multi-dimension structure. As it mentioned before, in this research the first determined factor is called psycho-physical violence, it seems that the psychological violence stems from low communication skills and a deficit in social problem solving that leads to impulsive behaviour. This explanation suggested that teaching social problem solving and communication skills can reduce domestic violence. Whitening et al. (2009) concluded that mental health problems can predict domestic violence. Mohammadkhani (2006) also showed that the psychic profile of domestic violence perpetrators have many problems, such as: low anger and conflict management skills, communication problems, sexual hostility, negative attribution, jealousy, and low self-control. It seems that psychological problems do not just appertain to men or women and some of the couples' problems often go along with psychological violence, such as humiliating, blaming, mocking and undermining a victim's self-worth and self-esteem.

As it mentioned earlier, one of the extracted factors of the domestic violence test appertained to control violence. Many people use violent behaviour because they cannot state their feeling and they cannot solve their daily problems (Abolmaali, Saberi, \& Haghshenas, 2011). Jackson’s coercive control (CC) theory (2009) represents a suitable explanation in this case. Based on this theory, this can be explained as sexual-economic violence. Control encompasses forms of regulation, isolation, and exploitation that limit a victim's option, transfer her (his) resources to the controller, ensure her dependence on him (her), and maximize the benefits of personal service. Control tactics affect this outcome through three means, primarily: by monopolizing the tangible and intangible resources needed to develop and enjoy personhood, by orchestrating a partner's behaviour through rules and by eliminating opportunities for the victim to outside anger support (Jackson, 2009: 168). CC theory is mostly progressive and it includes unfair behaviour, 
Table 2.

Factorial load and the degree of left common questions.

\begin{tabular}{|c|c|c|}
\hline Questions & \multicolumn{2}{|c|}{ Factor load and communality } \\
\hline Questions of first factor & Factor load & Communality \\
\hline 1. He (she) shouts at me and says I am a fool. & 0.5 & 0.27 \\
\hline 2. He (she) makes me feel humiliated. & 0.46 & 0.22 \\
\hline 3. He (she) blames me for his anger. & 0.53 & 0.30 \\
\hline 4. He (she) insults the ones I love. & 0.67 & 0.46 \\
\hline 7. He (she) gets angry at every situation. & 0.59 & 0.37 \\
\hline 12. He (she) makes me responsible for his problems. & 0.54 & 0.32 \\
\hline 15. He (she) does not care about my comments. & 0.57 & 0.35 \\
\hline 16. He (she) shouts at me. & 0.66 & 0.44 \\
\hline 17. He (she) calls me using bad language. & 0.60 & 0.76 \\
\hline 18. He (she) does not care about my interests. & 0.63 & 0.48 \\
\hline 19. He (she) does not respect my feelings. & 0.69 & 0.51 \\
\hline 20. He (she) insults me using bad language. & 0.41 & 0.21 \\
\hline 21. He (she) gets annoyed about my family relations. & 0.58 & 0.48 \\
\hline 22. He (she) does not respect me near others. & 0.43 & 0.21 \\
\hline 23. He (she) makes others angry with me. & 0.45 & 0.21 \\
\hline 24. He (she) pushes me when he is angry. & & \\
\hline 26. He (she) throws my personal objects when he (she) is angry. & 0.47 & 0.28 \\
\hline 27. He (she) loves revenging. & 0.46 & 0.22 \\
\hline 28. He (she) threatens me with divorce. & 0.59 & 0.36 \\
\hline 33. He (she) comes near me only to sleep or to eat lunch. & 0.57 & 0.33 \\
\hline 34. He (she) changes his bed for tiny things. & 0.43 & 0.29 \\
\hline 35. He (she) does not care about my sadness. & 0.62 & 0.41 \\
\hline 36. He (she) does not care about my illness. & 0.57 & 0.35 \\
\hline 37. I (she) tolerate him just for my shame. & 0.67 & 0.45 \\
\hline 38. He (she) swears at me when he (she) is anger. & 0.81 & 0.68 \\
\hline 39. He (she) swears at my family. & 0.75 & 0.56 \\
\hline 40. I do not mention my problems for his annoyance. & 0.40 & 0.56 \\
\hline 41. He (she) stops my progression. & 0.34 & 0.59 \\
\hline 42. He (she) kicks me. & 0.48 & 0.33 \\
\hline Questions of second factor & Factor load & Communality \\
\hline 5. He (she) forces me to do unfavourable things. & 0.52 & 0.24 \\
\hline 6. He (she) controls my behaviour and actions. & 0.45 & 0.21 \\
\hline 8. He (she) stops me going out independently. & 0.42 & 0.21 \\
\hline 9. He (she) confines me for making purchases. & 0.52 & 0.27 \\
\hline 10. He (she) stops visiting my family and friends. & 0.44 & 0.23 \\
\hline 11. He (she) blames me for buying. & 0.49 & 0.27 \\
\hline 13. When sex time, he (she) does not care about my tiredness. & 0.44 & 0.21 \\
\hline 14. He (she) gets anger when it is sex time. & 0.38 & 0.23 \\
\hline 37. He (she) controls my text messages. & 0.49 & 0.25 \\
\hline 25. He (she) is curious about my calls. & 0.63 & 0.36 \\
\hline 29. He (she) looks in my purse. & 0.47 & 0.22 \\
\hline 30. He (she) puts me under pressure to make a lot of money. & 0.40 & 0.27 \\
\hline 31. His (her) material requests are not adapted to mine. & 0.43 & 0.21 \\
\hline 32. I cannot spend my money without his (her) permission. & 0.39 & 0.21 \\
\hline
\end{tabular}


Table 3.

Row scores, $\mathrm{z}$ scores and $\mathrm{T}$ scores.

\begin{tabular}{|c|c|c|c|c|c|c|c|}
\hline \multicolumn{8}{|c|}{ Raw, Z, and T scores } \\
\hline Raw score in factor 1 & $\mathrm{~T}$ & Raw score in factor 1 & $\mathrm{~T}$ & Raw score in factor 1 & $\mathrm{~T}$ & Raw score in factor 1 & $\mathrm{~T}$ \\
\hline 39 & 83 & 26 & 69.5 & 16 & 59 & 6 & 48 \\
\hline 38 & 5.82 & 25 & 68.5 & 15 & 58 & 5 & 47 \\
\hline 37 & 81 & 24 & 67.5 & 14 & 57 & 4 & 46 \\
\hline 36 & 80 & 23 & 66 & 13 & 56 & 3 & 45 \\
\hline 35 & 79 & 22 & 65 & 12 & 54.5 & 2 & 44 \\
\hline 34 & 78 & 21 & 64 & 11 & 53.5 & 1 & 43 \\
\hline 33 & 77 & 20 & 63 & 10 & 52.5 & 0 & 42 \\
\hline 30 & 74 & 19 & 62 & 9 & 51 & & \\
\hline 29 & 73 & 18 & 61 & 8 & 50 & & \\
\hline 28 & 72 & 17 & 60 & 7 & 49 & & \\
\hline
\end{tabular}

regular tactics for controlling the partner and reinforces gender stereotypes. Finally it leads to the destruction of self-autonomy. Jackson believes that based on this theory, one partner controls another one with this violence.

Based on the findings, the mean difference of coercive control in women was higher than men. That is, women are put under more coercive control (MirMajidi, 2009). In Reality men apply violence as a tool for controlling the behaviour of a female until she obeys him. It seems that control violence is laid on the male's cultural background. According to the gender stereotype existing in our society and the related women's expectations in relation to their pains and problems, with regard to this they would give their dissatisfaction causing the increase of their coercive control.

It seems that one of the most particular challenges of our society is related to the lack of knowledge in relation to domestic violence. Based on the obtained factors in this research, it can be defined that domestic violence is based on real data. For this reason, the first factor represents the psycho-physical violence in the study that is shown as physical and verbal violence with regard to this. According to the content of the research questions, those behaviours with disrespect, swearing and insulting and other impulsive behaviours such as pushing and kicking are called violence with regard to this. The coercive control is a symbol of compulsive control and is defined with behaviours like prevention of the spouse from family meetings or friends, control over comings and goings, controlling telephone communications, texts and the spouse's private belongings, forcing economic issues and sexual relationships.

It is recommended to apply some supportive and social approaches in relation to the psycho-physical violence for both genders. Moreover, making a great information base for awakening people in relation to domestic violence is an essential factor in the prevention of the problem in society. Therefore, holding group educational sessions, educational workshops and different scientific seminars are suggested with regard to this.

\section{Conclusion}

The results of this research showed that, the self-reported questionnaire of domestic violence can measure two dimensions (based on factor analysis): 1) Psycho-physical violence, 2) Control violence (sexual, economic and coercive violence).
This test has good validity and reliability. The criterion validity of this scale was significant and this scale had a significant relationship with the quality of marital life test. In addition, this test has suitable differential validity, so that this test has the ability of separation in people with domestic violence from normal ones.

The entire reliability of the domestic violence test and its two dimensions with internal consistency and test-retest method is suitable. Also for comparing scores of different individuals, Z standard scores and $\mathrm{T}$ standardized scores are calculated for total scores test and separately in relation to each factor.

One of the most important features of the test is subjected to the low numbers of questions and the possibility of its easy administration on groups or individuals and this test can be used for the nonclinical population. Thus, it can be completed on married college students as well. According to the validity and reliability of this scale, it is suggested that this questionnaire can be applied to the diagnosis of domestic violence dimensions as well. But like every other test, this should only measure the samples of the behaviour and using it as an only diagnostic tool is not recommended. In addition, it can be applied in research-based activities.

\section{REFERENCES}

Abolmaali, K. H. (2012). The construction and standardization of aggressive scale. The Psychometric Journal of Islamic Azad University, Roudhen Branch, 1, 5-25.

Abolmaali, K. H., \& Mousazadeh, Z. (2012). The aggression: The nature, causes, and prevention. Tehran: Arjmand.

Abolmaali, Kh., Saberi, H., \& Haghshenas, T. (2011). Conference of the role of specialist in prevention of crime. http://www.pishgiri-iau.ir/khouzestan/userfiles/file/abolmaali.doc

Aghabigloie, A., Aghajani, K., \& Chehreii, A. (2002). Evaluation physical violence by spouse against women refering to forensic medicine of Tehran. Iranian Journal of Medical Science, 9, 485-490.

Andarabi, Z. (2009). Prevention of women offence against domestic violence, by the struggle of Mohammad Farajiha and Abbas Sheikhaleslami. The abstract articles of applied-scientific national conference in the prevention of Judiciary criminals. Mashad.

Arshi, M. (2004). The study of effective factors on spouse-offending violence tolerance in Tehran in 2003. Tehran Wellfare project.

Bagharzaiee, P. (2003). The study of effective factors on men violence degree towards women, Ilam City. Ma Dissertation. Allameh Tababaiee university, Tehran. 
Belali-Meibodi, F., \& Hassani, M. (2009). The distribution of violence against women by their mates in Kerman City. Psychology and CliNical Psychology Journal, 15, 300-307.

Belmont, J. (2008). Domestic violence and abuse.

Campbell, J. C. (2003). Risk factor for homicide in abusive relationship: Results from a multisite case control study. American Journal of Public Health, 93, 1089-1097. http://dx.doi.org/10.2105/AJPH.93.7.1089

Family Violence Prevention Fund (1999). Preventing domestic violence: Clinical guidelines on routine screening. San Francisco, CA: Family Violence Prevention Fund.

Fatthi, H. (2000). The study of violence situation towards women in tehranian families. MA Dissertation, Tehran University.

Gannon, A., Ward, T., Beech, A. R., \& Fisher, D. (2007). Aggressive offenders' cognition. Chichester: John Willy \& Sons, Ltd. http://dx.doi.org/10.1002/9780470746295

Goudbout, N., Dutton, D. G., Lussier, Y., \& Sabourin, S. (2009). Early exposure to violence, domestic violence, attachment representations and marita adjustment. Personal Relationships, 16, 365-384. http://dx.doi.org/10.1111/j.1475-6811.2009.01228.x

Higginbotham, B. J., Ketring, S. A., Hibbert, J., Wright, D. W., Guarino, A., Goudbout, N., Dutton, D. G., Lussier, Y., \& Sabourin, S. (2009). Early exposure to violence, domestic violence attachment representations and marital adjustment. Personal Relationships, 16, 365-384. http://dx.doi.org/10.1111/j.1475-6811.2009.01228.x

Hollin, C. R., \& Bloxsom, C. A. J. (2007). Treatments for angry aggression. In T. A. Gannon, T. Ward, A. R. Beech, \& D. Fisher (Eds.), Aggressive offenders' cognition. Chichester: John Willy \& Sons, Ltd. http://dx.doi.org/10.1002/9780470746295.ch11

Jackson, A. N. (2009). Encyclopaedia of domestic violence. Routledge: New York and London.

Keeling, J., \& Mason. (2009). Domestic violence: A multi-professional approach for healthcare practitioners. Open University Press.

Kinnear, P. A., \& Gray, C. D. (2004). SPSS 12 made simple. Hove and New York: Psychology Press.

Mahmoud, G. M., Mohseni, T. A., Marjani, S. H., \& Shaditalab, Z. (2003). The study of domestic violence against women. Tehran: Moje Aval.

Marabi, M. (2005). The study of effective factors of family in the violence against women in Kamyaran County. MA Dissertation, Tehran: Allameh Tababaeiee University.

Mariuro, R. D. (2001). But names will also hurt me: Psychological abuse in domestically relationships. In K. D. O’Leary, \& R. D. Mariuro (Eds.), Psychological abuse in violent domestic relations (pp. viiix). New York: Springer Publishing Company, Inc.

Mertous, J. (2003). The education of women and girls' humanistic rights. Translated by Fariborz Majidi, Tehran: Donyaye Madar.

MirMajidi, S. (2009). Physical domestic violence and its prevention methods by the struggle of Mohammad Farajiha and Abbas Sheikhaleslami. The abstract articles of national applied-scientific research centre in the prevention of Judiciary criminals, Mashad.
Mohammadkhani, P., \& Azadmehr, H. (2008). The pathology and personal-relation problems of sacrificed women. Seasonal Scientific Journal of Social Wealth Centre, 7, 65-74.

Mohammadkhani, P. (2005). The report of domestic violence, with emphasis on the determination of spouse-offending issues: Psychological aspects and psychopathology. Medical Sciences Research Centre and Rehabilitation Centre. Tehran: The National Medical Sciences Research Centre.

Moore, E. N. (2008). Domestic violence against men. Bloomington: Authorhouse.

Ramirez, M. J. (2003). Human aggression: A multifaceted phenomenon. Madrid: Centreur.

Rodriguez, C. M. (2006). Emotional functioning, attachment style, and attribution as predictors of child abuse potential in domestic violence victims. Violence and Victims, 21, 199-212. http://dx.doi.org/10.1891/vivi.21.2.199

Saberi, H. and Abolmaali, K. H. ( 2012). Standardization of life quality test. Research Project in Islamic Azad University, Roudhen Branch.

Saeidzadeh, Z. (2009). Sacrifices women of violence. Irandokht Weekly Paper, 27, 14.

Simmons, C. A., Lehmann, P., \& Collier-Tenison, S. (2008). Women arrested for IPV offenses: Abuse experiences yet low trauma pathology. Journal of Family Violence, 23, 755-765. http://dx.doi.org/10.1007/s10896-008-9200-9

Sterne, A., Poole, L., Chadwick, D., Lawler, C., \& Dodd, L. W. (2010). Domestic violence and children. London: Routledge.

Taheri, S. H. (1999). The study of violence quality degree against women. Zandjan: Khodabandeh Count Legal Medicine Centre. [Persian].

Webster, C. D., \& Hucker, S. J. (2007). Violence risk assessment and management. Chichester: John Wiley \& Sons, Ltd.

Winters, J., Clift, R. J. W., \& Dutton, D. G. (2004). An explanatory study of emotional intelligence and domestic abuse. Journal of Family Violence, 19, 255-265. http://dx.doi.org/10.1023/B:JOFV.0000042076.21723.f3

Whiting, J. B., Simmons, L. A., Havens, J. R., Smith, D. B., \& Oka, M. (2009). Intergenerational transmission of violence: The influence self-appraisals, mental disorders and substance abuse. Journal of Family Violence, 24, 639-648. http://dx.doi.org/10.1007/s10896-009-9262-3

Winters, J., Clift, R. J. W., \& Dutton, D. G. (2004). An explanatory study of emotional intelligence and domestic abuse. Journal of Family Violence, 19, 255-265. http://dx.doi.org/10.1023/B:JOFV.0000042076.21723.f3

Zosky, D. L. (1999). The application of object relations theory to domestic violence. Clinical Social Work Journal, 27, 55-69. http://dx.doi.org/10.1023/A:1022861331105 